\title{
KINEMATICS OF THE V MECHANISM USED FORELECTRIC SWITCHERS BASED ON SPECIALISED SOFTWARE

\author{
PĂUN ANTONESCU ${ }^{1}$, LIVIU-MARIAN UNGUREANU ${ }^{* 2}$, COSTANTIN \\ BREZEANU ${ }^{3}$
} \\ ${ }^{1,2}$ University Politehnica of Bucharest, Splaiul Independenţei 313, sector 6, Bucureşti, 060042, Romania
}

${ }^{3}$ Silcotub S. A. (Tenaris Group) of Călărași, Romania

\begin{abstract}
This paper is representing a continuing research of the doctoral thesis "Geometrical analysis and synthesis of mechanisms in the electrotechnical field". Using two Mathcad programs as mathematics analysis software and Solidworks as graphical analysis software it is dimensioned the new kinematics scheme of the high voltage $\mathrm{V}$ mechanism. Kinematic analysis is based on the mathematical model presented in the doctoral thesis mentioned above and graphical modeling and analysis is conducted to compare and complete the research regarding the $\mathrm{V}$ mechanism triadic chain $5 \mathrm{R}+\mathrm{T}$ type.
\end{abstract}

Keywords: kinematic scheme, geometrical analysis, mathematical model, triadic chain

\section{INTRODUCTION}

The doctoral thesis [1] presents from a theoretical point of view the $\mathrm{V}$ mechanism for the high voltage electric switcher. Also, a new diagram shows this mechanism (Figure 1). The initial mechanism was formed of two dyadic chains that have been configured into a triadic chain $[1,2,3]$.

Since the electric field is continually evolving, it has been considered necessary to carry on research on the V mechanism formed of 2 triadic chains of the $5 \mathrm{R}+\mathrm{T}$ type.

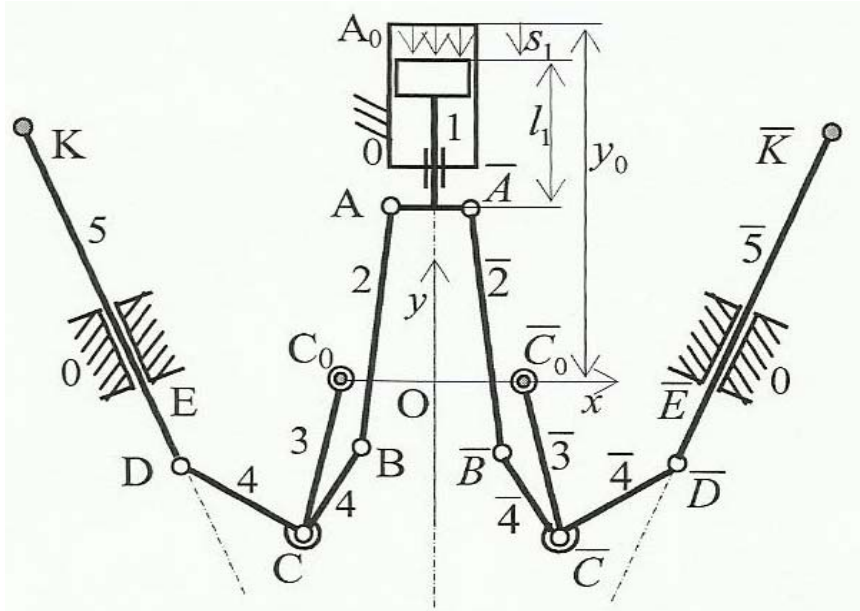

Fig. 1. The kinematic diagram of the V mechanism.

\footnotetext{
* Corresponding author, email: ungureanu.liviu.marian@gmail.com

(C) 2015 Alma Mater Publishing House
} 
The mechanism uses articulated bars moving in a plane. The kinematic couplings of the leading kinematic element (kinematic element 1) and of the exit kinematic element 5 have a translational motion.

This is a plane mechanism of the III family, and its mobility degree is determined by means of the CebâşevGrübler formula [2]:

$$
M_{3}=3 n-2 C_{5}-C_{4}
$$

where:

- $\mathrm{n}$ represents the number of mobile kinematic elements;

- the number of $\mathrm{V}$ class plane kinematic joints;

- the number of IV class plane kinematic joints.

The mobile elements shall be identified on the kinematic diagram by means of numbers $(1,2,3,4,5,6,7)$ starting with the input element. The fixed element shall be identified by means of 0 (Figure 1). The mechanism has only $\mathrm{V}$ class joints (rotation and translational). These are identified by means of capital letters, in association with the structural number. The mechanism has $\mathrm{n}=9, \mathrm{C}_{5}=13, \mathrm{C}_{4}=0$. By means of introducing these structural parameters in the equation $(1)$ it results the mobility $(\mathrm{M} 3=1)$, while the mechanism has a single input element, piston 1 that leads movement to the two triadic kinematic chains at the same time.

\section{THE GEOMETRICAL KINEMATIC CALCULATION OF THE PLANAR MECHANISM WITH A TRIADIC CHAIN TYPE 5R+T USING MATHEMATIC CALCULATION SOFTWARE}

For the geometrical and kinematic analysis of the proposed mechanism the following geometrical dimensions of the elements (Table 1) have been chosen.

Table 1. Geometrical dimensions of the elements.

\begin{tabular}{|l|l|l|l|l|}
\hline$l_{1}=0.047[\mathrm{~m}]$ & $l_{3}=0.055[\mathrm{~m}]$ & $l_{4}^{1}=0.028[\mathrm{~m}]$ & $\mathrm{e}=0.05[\mathrm{~m}]$ & $\mathrm{XC} 0=-0.035[\mathrm{~m}] \mathrm{YC} 0=0$ \\
\hline$l_{2}=0.075[\mathrm{~m}]$ & $1_{4}=0.038[\mathrm{~m}]$ & $\mathrm{s}_{1}=0 \ldots 0.015[\mathrm{~m}]$ & $\mathrm{XA} 0=0 ; \mathrm{YA} 0=0.09[\mathrm{~m}]$ & $\mathrm{XE}=-0.085[\mathrm{~m}] ; \mathrm{YC} 0=0$ \\
\hline
\end{tabular}

The geometrical kinematic analysis is based on the method of vector contour lines. The triadic chain LT $(2,3,4$, 5) shall be isolated.

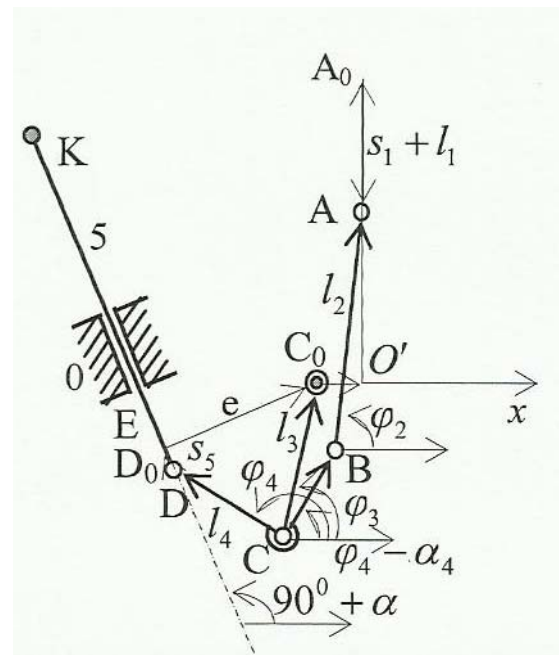

Fig. 2. The associated vector contour lines.

Then we identify two vector contour lines associated to this kinematic chain, namely $\mathrm{O}^{\prime} \mathrm{A}_{0} \mathrm{ABCC}_{0} \mathrm{O}^{\prime}$ and $\mathrm{C}_{0} \mathrm{CDD}_{0} \mathrm{C}_{0}$, each side is suitably oriented and placed by means of the trigonometrically oriented angle (Figure 2 ). For these contour lines, we write the vector closing equations: 


$$
\begin{aligned}
\left(\mathrm{O}^{\prime} \mathrm{A}_{0} \mathrm{ABCC} \mathrm{O}^{\prime}\right) & : \overrightarrow{O^{\prime} A_{0}}+\overrightarrow{A_{0} A}-\overrightarrow{B A}-\overrightarrow{C B}+\overrightarrow{C C_{0}}+\overrightarrow{C_{0} O^{\prime}}=0 \\
\left(\mathrm{C}_{0} \mathrm{CDD}_{0} \mathrm{C}_{0}\right) & : \overrightarrow{C C_{0}}-\overrightarrow{C D}-\overrightarrow{D D_{0}}-\overrightarrow{D_{0} C_{0}}=0
\end{aligned}
$$

The scaling equations related to the vector equations are:

$$
\begin{aligned}
& l_{2} \cos \varphi_{2}+l_{4}^{\prime} \cos \left(\varphi_{4}-\alpha_{4}\right)-l_{3} \cos \varphi_{3}=C_{0} O^{\prime} \\
& l_{2} \sin \varphi_{2}+l_{4}^{\prime} \sin \left(\varphi_{4}-\alpha_{4}\right)-l_{3} \sin \varphi_{3}=y_{0}-l_{1}-s_{1} \\
& l_{3} \cos \varphi_{3}-l_{4} \cos \varphi_{4}-s_{5} \cos \left(90^{\circ}+\alpha\right)=e \cdot \cos \alpha \\
& l_{3} \sin \varphi_{3}-l_{4} \sin \varphi_{4}-s_{5} \sin \left(90^{\circ}+\alpha\right)=e \cdot \sin \alpha .
\end{aligned}
$$

The system consists of four scaling equations with four unknown variables out of which 3 are the angular displacements $\left(\varphi_{2}, \varphi_{3}, \varphi_{4}\right)$ and a linear displacement $\left(s_{5}\right)$

To determine the above we have used specialised software Mathcad [5] based on the method of consecutive approximations and the method of the smallest squares to solve the system. Several values are given for angular displacements, but we selected only those that allow for the continuity of the motion.

With regard to the dimensions of the above-mentioned elements with a linear displacement $\left(\mathrm{s}_{1}=0-0.010 \mathrm{~m}\right)$ Corresponding to the leading element, we have obtained the following values graphically presented in Figure 3 $\mathrm{a}, \mathrm{b}, \mathrm{c}, \mathrm{d}$ for angular displacements $\left(\varphi_{2}, \varphi_{3}, \varphi_{4}\right)$ and linear displacements $\left(\mathrm{s}_{5}\right)$.
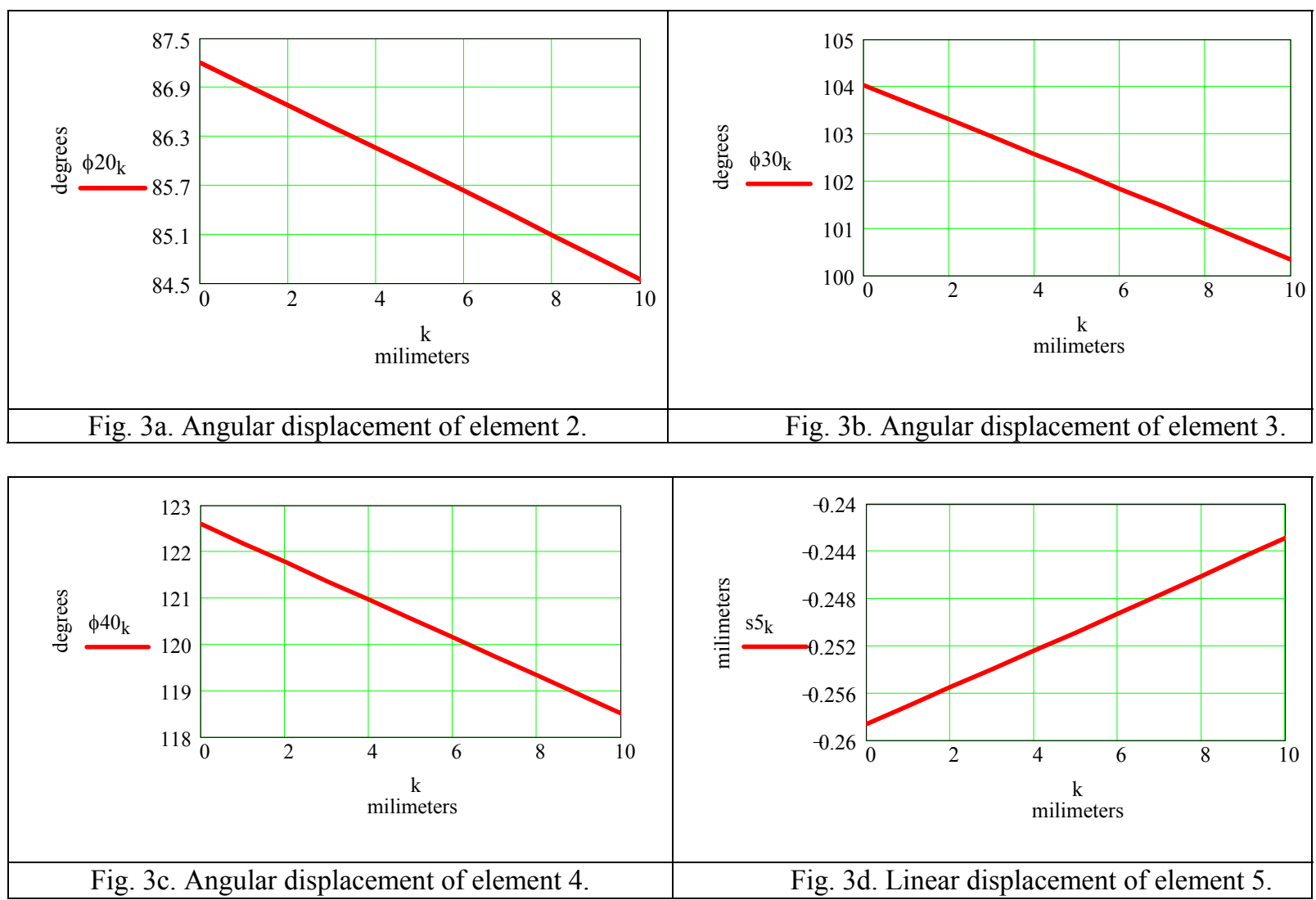

As we can notice in each diagram (Figure 3a, b, c, d), displacements look almost linear. This is due to the geometric dimensions of the kinematic elements. 


\section{CALCULATION OF THE GEOMETRICAL KINEMATIC PLANAR MECHANISM WITH A TRIADIC CHAIN 5R+T USING GRAPHIC SOFTWARE}

Prior to designing a prototype of the $\mathrm{V}$ mechanism used for high voltage switches, the 3D graphic modelling can be done using specialized software. We have used the graphic software Solidworks [6], and for the mechanism in Figure 1, each kinematic element has been modelled using the „Part” module. Then, using the „Assemblies” module, the assembling has been carried out, uniting all the elements and introducing the constraints given by the kinematic couplings (Figure 4a). Since this is a symmetric chain mechanism, we have selected the geometrical modelling of the vector contour lines presented in Figure 2.

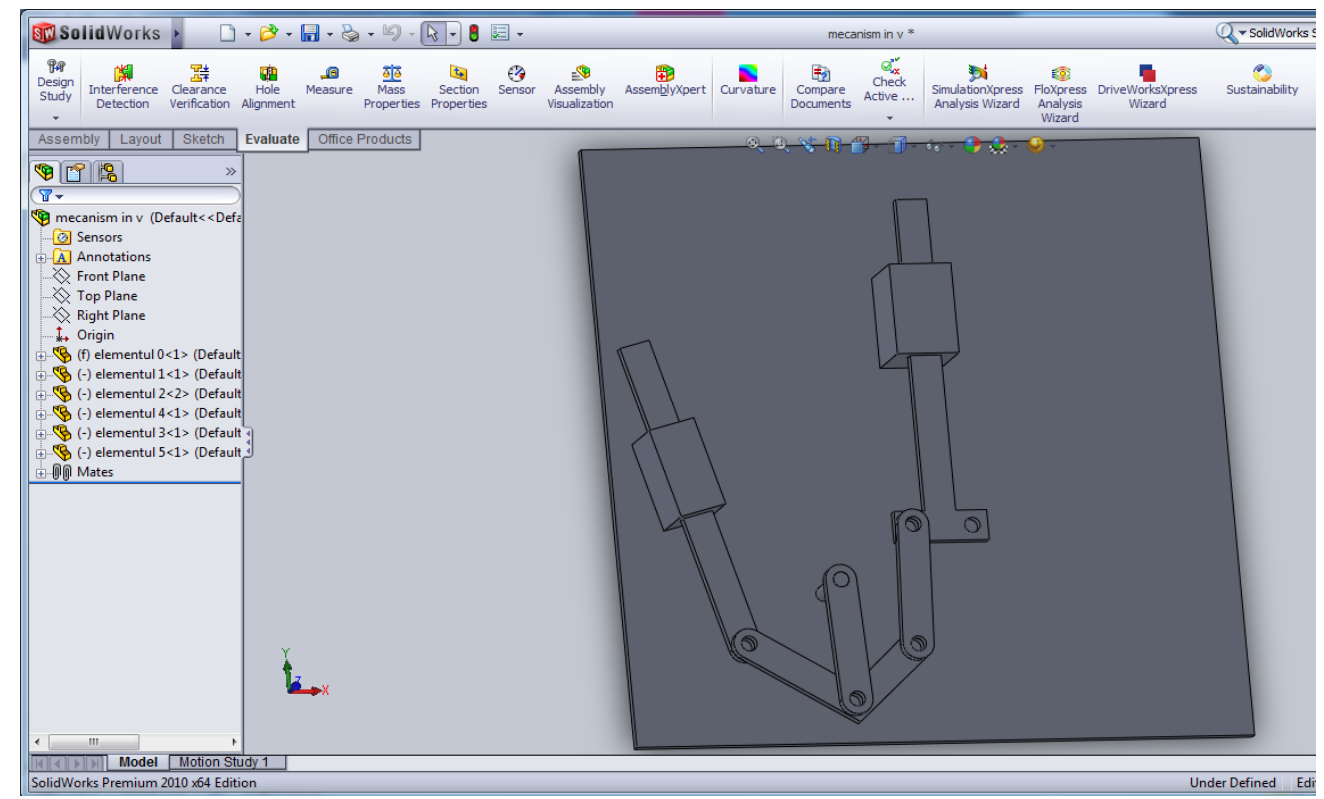

Fig. 4a. The V mechanism used for high voltage switches modelled with Solidworks.

Having done the 3D graphic modelling of the mechanism with the Solid Motion module, we can determine the displacements of the elements depending on the piston 1 path. We select a linear actuator to carry out the piston path (Figure $4 \mathrm{~b}$ ) and the axis along which the motion occurs.

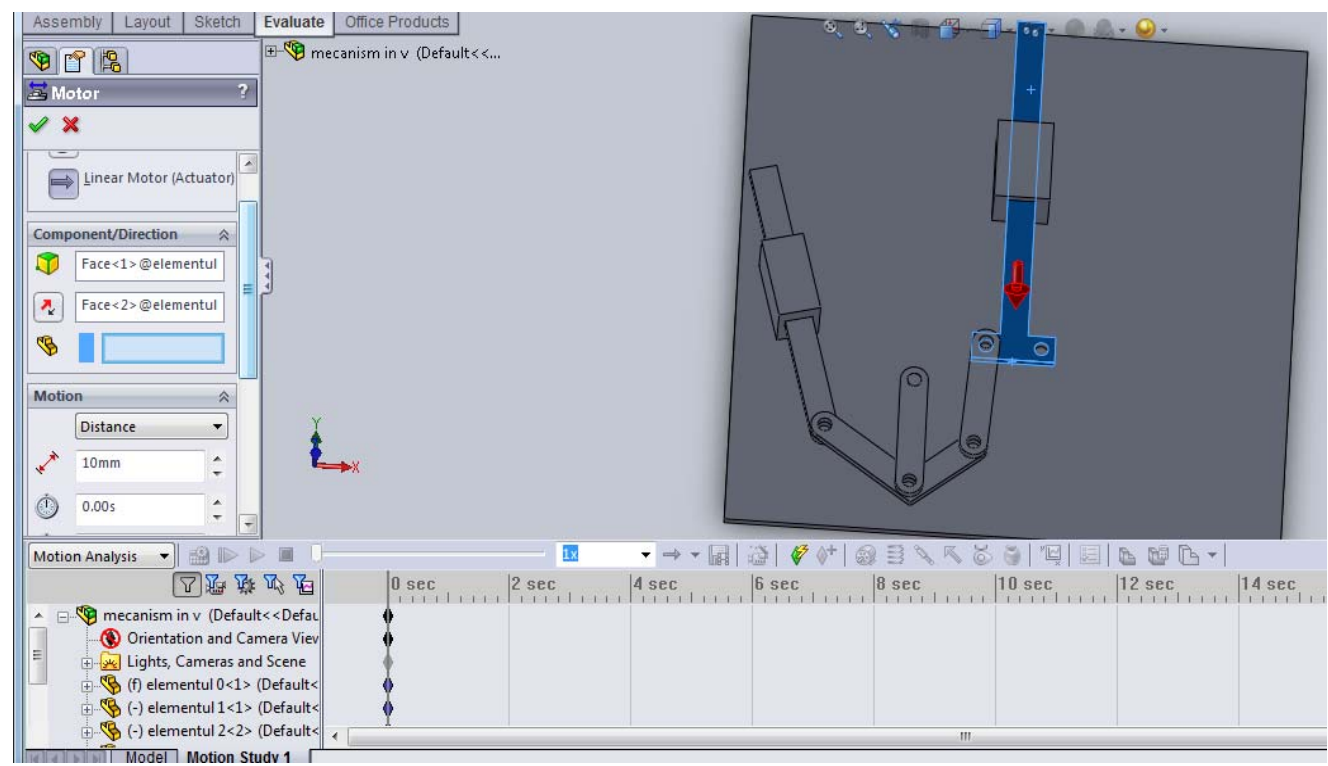

Fig. 4b. Selecting the piston path and the axis along which the displacement occurs.

The results obtained with the graphic software are presented in Figure 5a, b, c, d. 


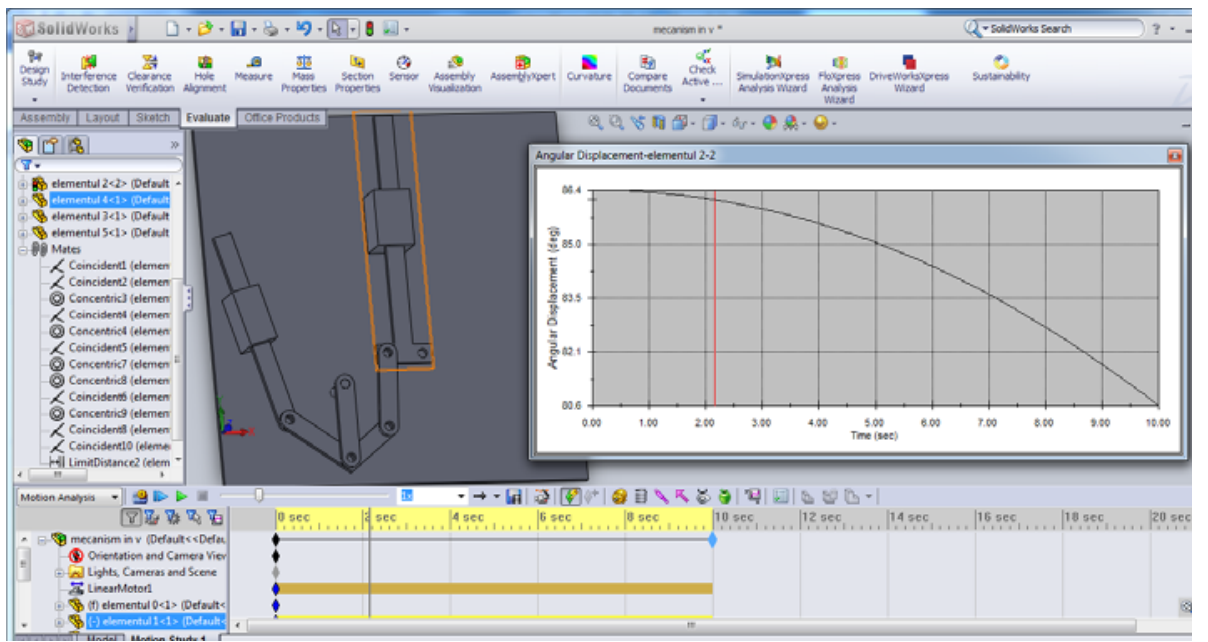

Fig. 5a. Angular displacement of element 2.

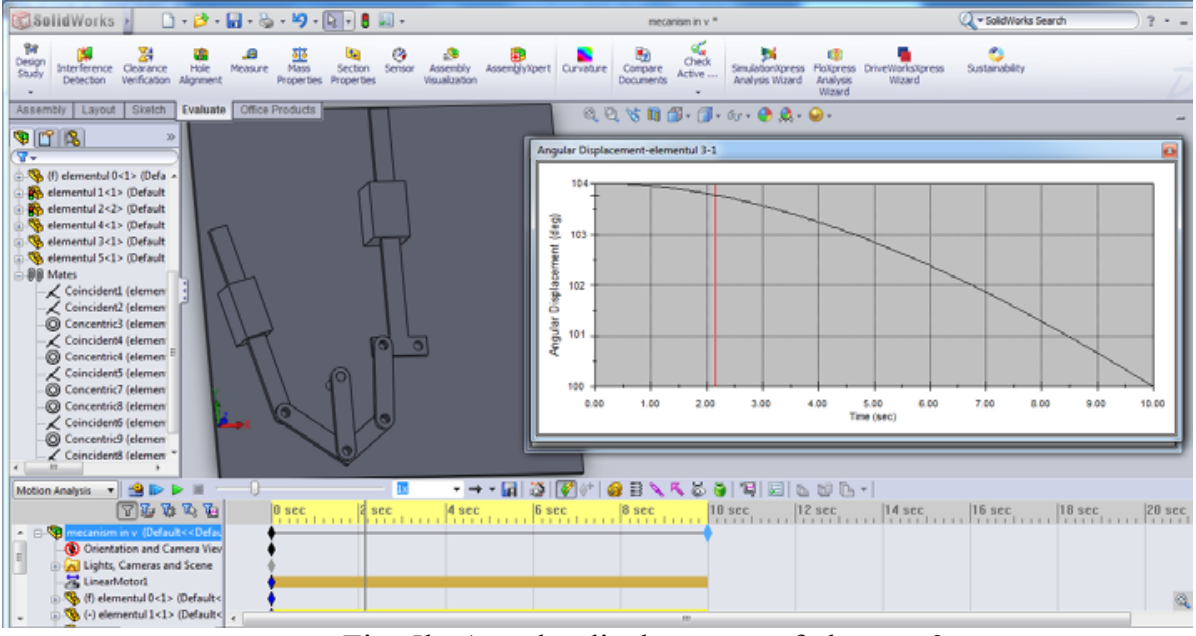

Fig. 5b. Angular displacement of element 3.

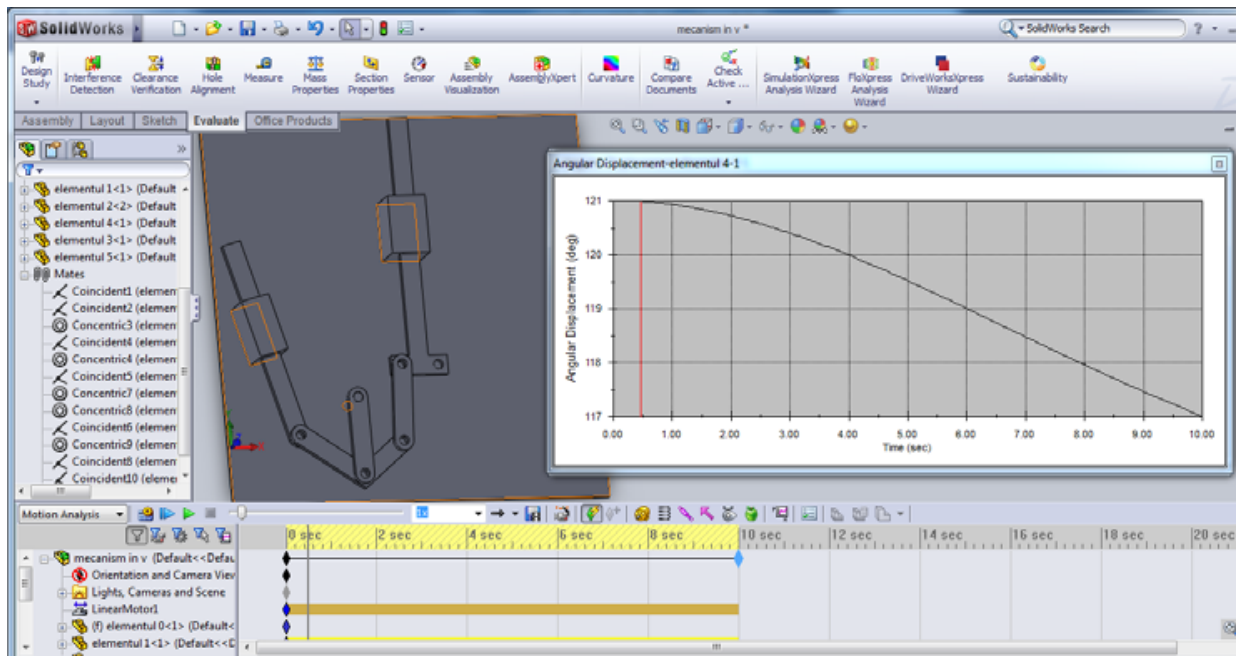

Fig. 5c. Angular displacement of element 4. 


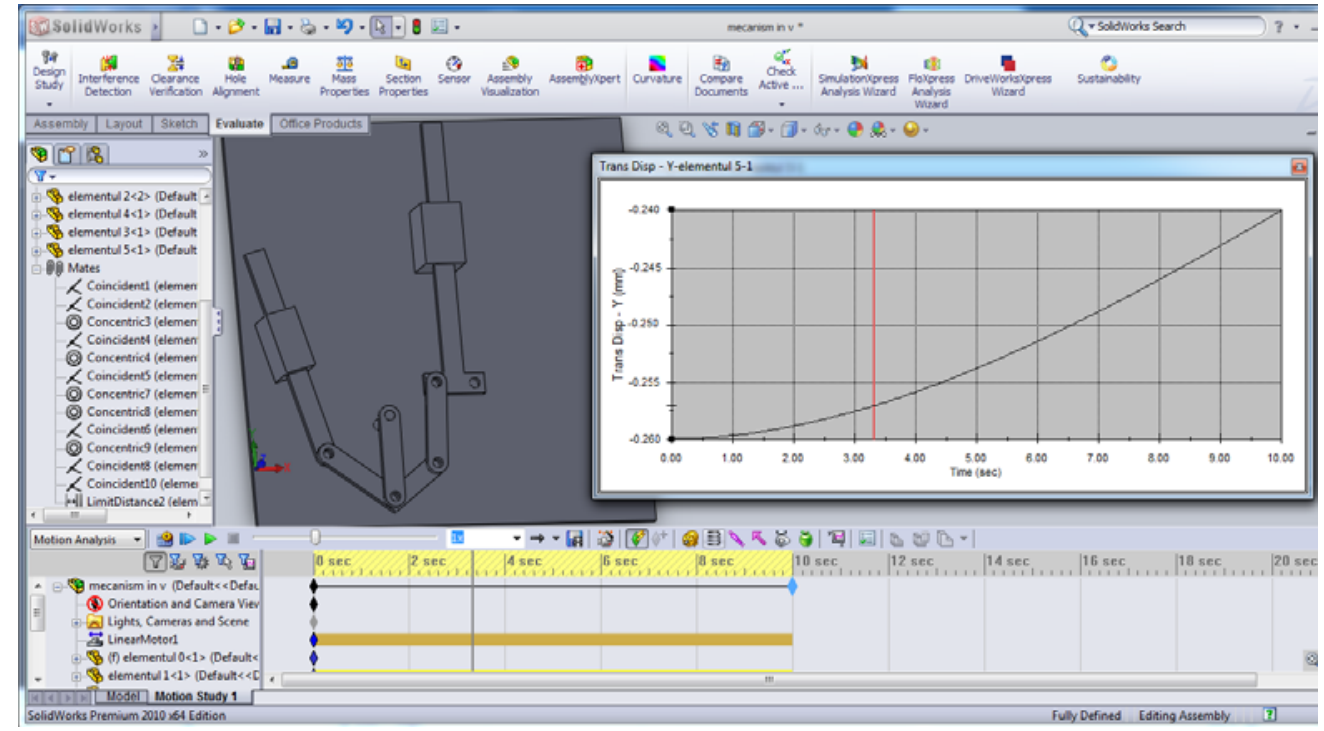

Fig. 5d. Linear displacement of element 5.

For the graphic representations, with the time variable, obtained with the help of Solidworks Motion, the linear displacement diagram of element 5 is not perfectly linear.

If we compare the linear displacements obtained by means of the mathematical model, used in the numerical calculation software, with those obtained by means of the graphic software, differences occur only starting with the $6^{\text {th }}$ decimal.

\section{CONCLUSIONS}

The kinematic analysis method presented is useful for obtaining optimal kinematic parameters and determining new constructive solutions.

This method of analysis, both numerical and graphic, can be used both for building plane manipulators and for spatial robots. By means of using two different analysis methods for a mechanism, one can minimize the errors due to subjective negligence.

\section{REFERENCES}

[1] Nedela, N., A geometrical analysis and synthesis of mechanisms in the electro technical field, Doctoral thesis, "Politehnica" University of Bucharest, 2012.

[2] Antonescu, P., Antonescu, O., Mechanisms and the dynamics of machines, Printech Publishing House, Bucharest, 2005.

[3] Nedela, N., Antonescu, O., Mechanisms used as medium voltage electric power switchers, Journal of Mechanisms and Manipulators, vol. 8, no 1, 2009.

[4] Nedela, N., Geonea, I., Mechanisms used for high voltage switch devices, Journal of Mechanisms and Manipulators, vol. 9, no. 1, 2010, p. 51-58.

[5] Mathcad - Finite element system. User Guide, 2012.

[6] Solidworks - Finite element system, User Guide, 2012. 